\title{
Trends in Atlantic Equatorial Current Variability
}

\author{
William J. Emery, Walter Zenk, Klaus Huber, Pierre Rual and Paul Nowlan
}

UDC 551.465.535:551.465.42; Atlantic Ocean

\begin{abstract}
Summary
Approximately twice-monthly expendable bathythermograph (XBT) sections between Europe and Brazil, are used to characterize trends in the equatorial geostrophic surface currents orthogonal to the sections between September, 1980 and May, 1984. Using mean temperature-salinity relationships the upper layer temperature profiles are converted to density and used to compute $0 / 300 \mathrm{db}$ dynamic height. Applying a second derivative method, at and near the equator, geostrophic surface currents are computed along each quasimeridional XBT section and time/space series of the equatorial currents are developed using spline interpolations in both time and space. Equatorial currents are mapped as time series of dynamic height and geostrophic current.
\end{abstract}

\section{Veränderlichkeiten im äquatorialen Stromsystem des Atlantiks (Zusammenfassung)}

Es werden zweimonatliche Bathythermographenschnitte zwischen Europa und Brasilien vom September 1980 bis Mai 1984 vorgestellt. Die Daten werden zur Darstellung eines mehrjährigen Trends im oberflächennahen äquatorialen Stromsystem verwandt, welches senkrecht zu den Schnitten liegt. Unter Ausnutzung einer mittleren Temperatur-Salzgehaltsbeziehung werden die Temperaturprofile in Dichteprofile überführt. Aus diesen wird die dynamische Tiefe $(0 / 300 \mathrm{dbar})$ errechnet. In Äquatornähe wird eine rechnerische Näherung für die geostrophischen Ströme verwandt. Ferner wird ein Spline-Interpolationsverfahren für die raumzeitliche Herleitung der quasi-meridionalen Strömungsverteilung genutzt. Das äquatoriale Stromsystem wird als eine Zeitserie der dynamischen Tiefe und der geostrophischen Ströme dargestellt.

\section{Variabilité du Courant a l'équateur dans Ocean Atlantique (Résumé)}

Des coupes thermiques au moyen de Bathythermographes à tête perdue (XBT) entre l'Europe et le Brésil environ deux fois par mois de septembre 1980 à mai 1984 sont utilisées pour caracteriser des tendances dans les courants géostrophiques équatoriaux perpendiculaires à ces coupes. Les profils de température dans les couches superficielles sont convertis en profils de densité au moyen de relations temperature-salinité moyennes, et permettent de calculer la hauteur dynamique 0/300 db. Après interpolation (spline) dans le temps et l'espace, on obtient une série spatio-temporelle, présentée sous la forme de cartes trimestrielles de hauteurs dynamiques et de courants géostrophiques. 


\section{Introduction}

There are a great many ship-of-opportunity (SOOP) expendable bathythermograph (XBT) sampling programs active today. Two such programs follow the shipping route from the southern limit of the English Channel across the equatorial Atlantic to Brazil. These programs are funded and organized separately by the Deutsches Hydrographisches Institut (DHI) and the French Ocean Research department (O.R.S.T.O.M.). The German program began in late 1980 while the French sampling effort (Rual and Jarrige, 1984) began a year later. Together these two XBT programs collected more than 100 XBT sections along very similar tracks - between mid-1980 and mid-1984.

The present paper uses these data to describe trends in the quasi-zonal currents associated with the upper-layer temperature structure measured by the repeated XBT casts. While it is true that SOOP XBT data are not precise and there are often gaps in the temperature profile coverage, the measurements from both of these programs present interesting variations in the meridional dynamic topography and hence the zonal geostrophic currents inferred from the XBT measured thermal structure. Such repeated measurements are expensive and difficult to acquire from research vessels and it is hoped that these results will be useful in extending our understanding of annual and interannual variations in the Atlantic equatorial currents and in providing suggestions for the analysis of other SOOP XBTdata.

\section{Data}

The XBT data used in this study were collected by German and French merchant vessels transiting between Europe and Brazil. Spacing between XBT casts is not uniform and varys from 100 to $300 \mathrm{~km}$. Often failed XBT drops are not repeated and large spatial gaps are created. At other times a section may be terminated prematurely or the data for a large part of the section are unusable. Still the continued coverage of these XBT sections represents a valuable monitoring resource for the study of variations in the Atlantic equatorial currents.

Since a great variety of ships, recorders and data logging procedures were used in the collection of these XBT data no effort was made to individually estimate instrument errors or their effects on our analysis. Internal consistency checks (between cast temperature differences, changes from climatology, etc.) were used to identify wildly erroneous temperature profiles which were eliminated from the analysis. In order to produce an analysis product smooth in space and time the input XBT data were fitted with a spline function to both smooth the meridional profiles and to provide values at latitudes not sampled by individual sections. An effort was made to compare the resulting spline-fit meridional dynamic height profiles with those calculated from the observations directly and the spline-fit parameters (tension, curvature, etc.) were adjusted so as to best represent the original input data.

The total data set is presented in Figs. 1 and 2 as a scatter plot of positions and as a latitude/time diagram of individual XBT casts. Most of the XBT positions lie upon one of two lines generally travelled by the ships. A few widely scattered positions can be seen which are location errors in the information recorded with the XBT cast. Such casts were eliminated if there were coincident problems with the XBT temperature profile itself. If the temperature data appeared meaningful the position along the section was computed as a projection on the mean track and the data used in the section.

It is important to note that our data have the potential of being noisy and the reader must remember that it is difficult to exercise strict statistical sampling limitations on data derived from this type of measurement program. A control of shipboard sampling procedures was not possible and thus one must use post-processing procedures to try and detect erroneuous samples. Such subjective editing methods are likely to both allow incorrect data to persist in the study and to perhaps eliminate some correct but apparently anomalous measurements from consideration. In our interpretation emphasis is placed on spatial and temporal averages which improve the statistical reliability of the end product. 


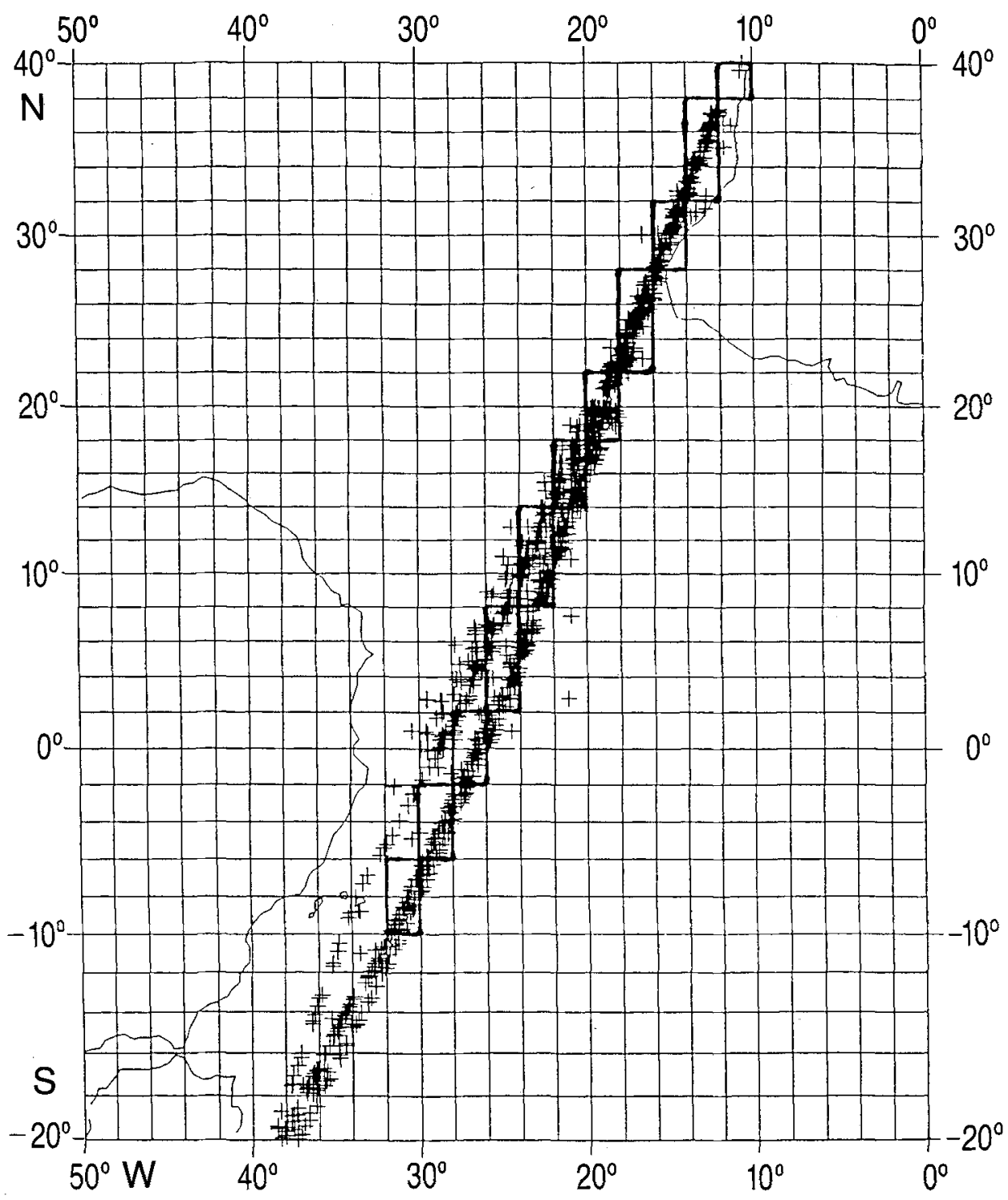

Fig. 1. Locations of XBT casts $(+)$ utilised in this study. 


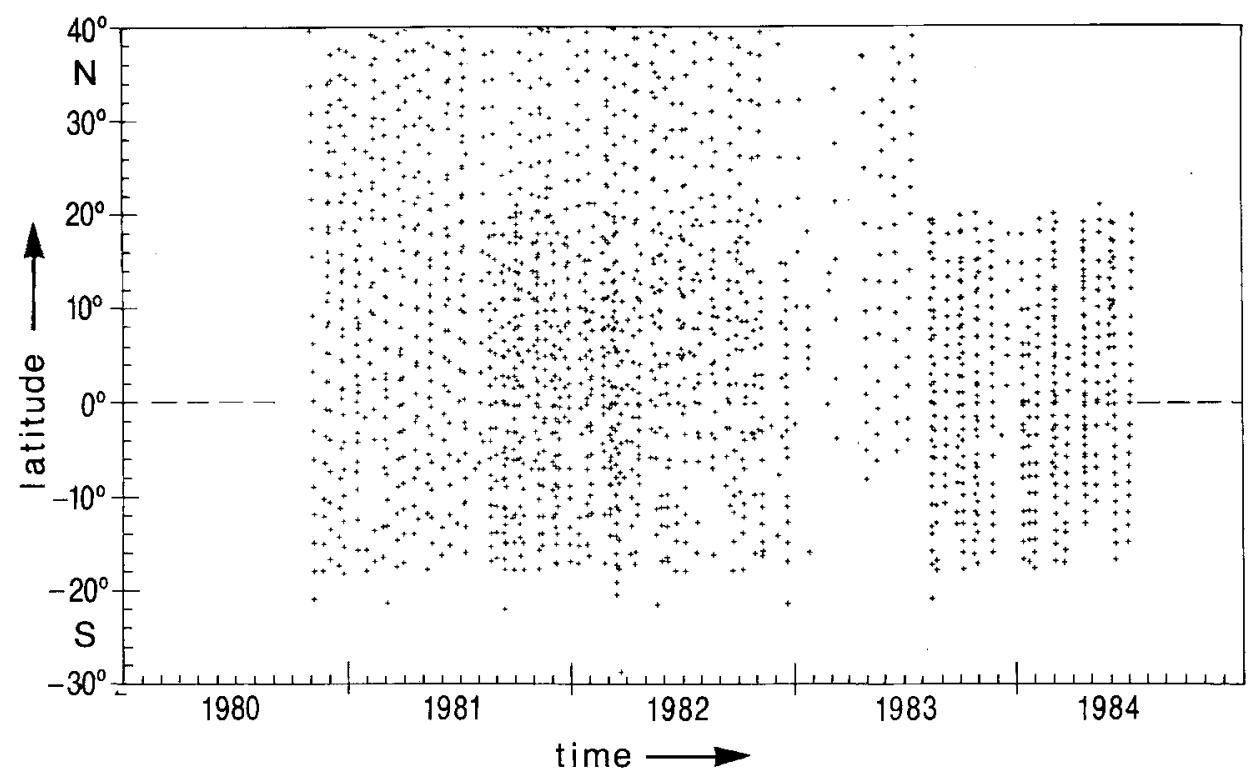

Fig. 2. Latitude/time diagram of all XBT drops that were analysed in this study.

\section{Computation of dynamic height and geostrophic velocity}

Since temperature is the primary variable in determining density in the equatorial Atlantic it was decided to use mean TS relationships from Em e r y and D ewar [1982] to convert the XBT data into density and dynamic height. This same method was used by Merle and Arnault [1985] to convert historical temperature profiles to density and dynamic height. They estimated the total error of this procedure for a $0 / 500 \mathrm{db}$ dynamic height, as $+/-2$ dyn $\mathrm{cm}$. Many of the present XBT casts terminated between 300 and $400 \mathrm{~m}$ and it was therefore decided to limit our dynamic height computations to the upper $300 \mathrm{~m}$ with a refrence level at $300 \mathrm{~m}$. The validity of this reference level was suggested by A rnault [1984] who concluded that the deep variability (i. e. $300 / 500 \mathrm{db}$ ) of geostrophic currents is small in this area. In order to get a smooth meridional dynamic height profile the resulting dynamic heights, at each XBT location, have been interpolated with spline functions to weekly values. The obtained quasi-meridional profiles were used for the rest of the analysis.

An example of these spline fits to the inferred dynamic topography profiles is shown in Fig. 3. The individual XBT data points are indicated by X's and the solid line represents the spline fit to these points. The points marked by $O$ signs are extracted each 2 degrees from the spline fit. As demonstrated by this example the spline fit represents the data well as long as the larger data gaps are not located at inflection points.

One problem, in using these XBT sections to compute geostrophic currents, is that the equator is located near the center of the sections. Due to the singularity of the Coriolis parameter at the equator it is impossible to use the first spatial derivative of the inferred dynamic heights, calculated from the XBT temperature profiles, to compute geostrophic velocity at the equator. To overcome this problem a technique introduced by Ts u chi y a [1955 a and b], recently used by Lukas and Firing [1984], was used to calculate geostrophic velocity at the equator by using the second derivative rather than the first to compute zonal velocity from the quasi-meridional sections. 


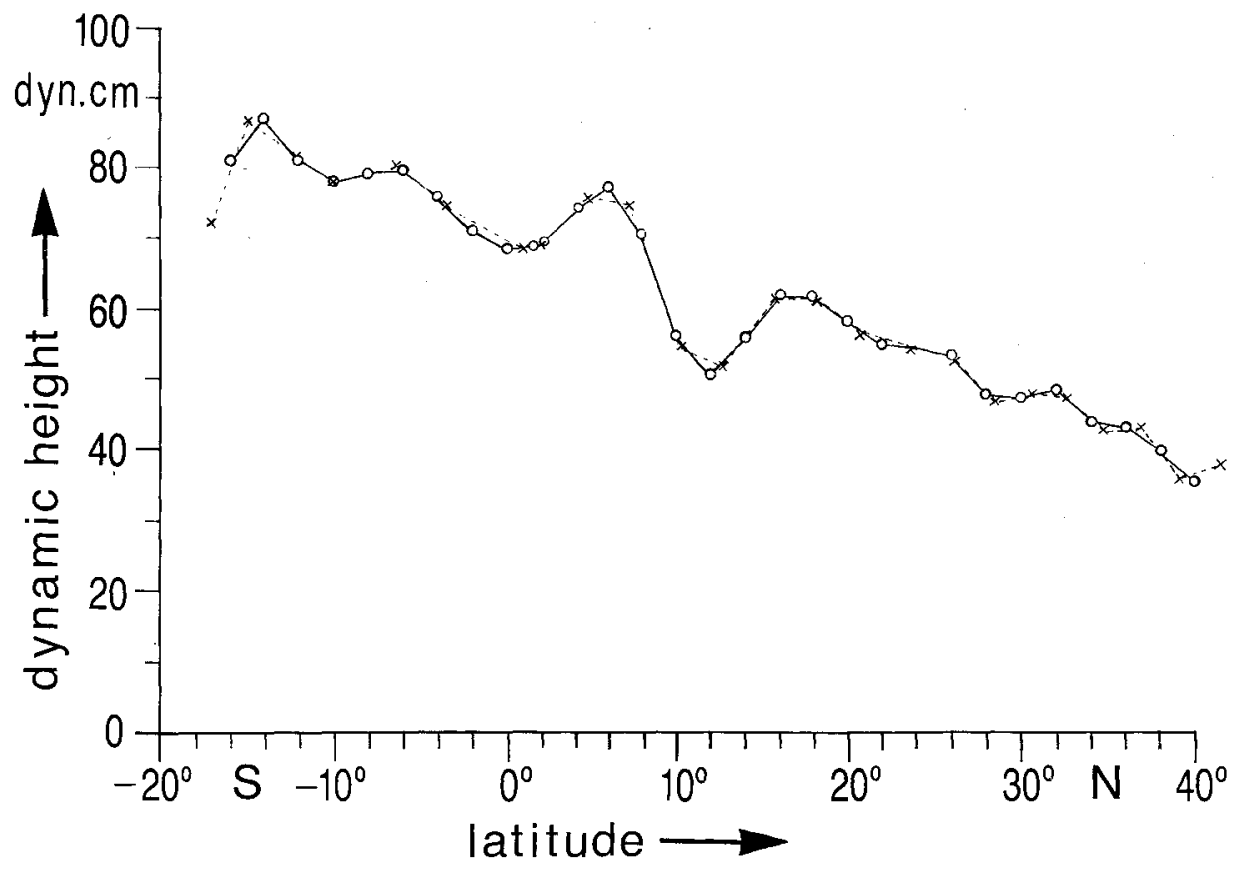

Fig. 3. An example of meridional dynamic height $(0 / 300 \mathrm{db})$ profiles. Data values are indicated by $(x)$ while $(O)$ signs locate the spline fit to the data points.

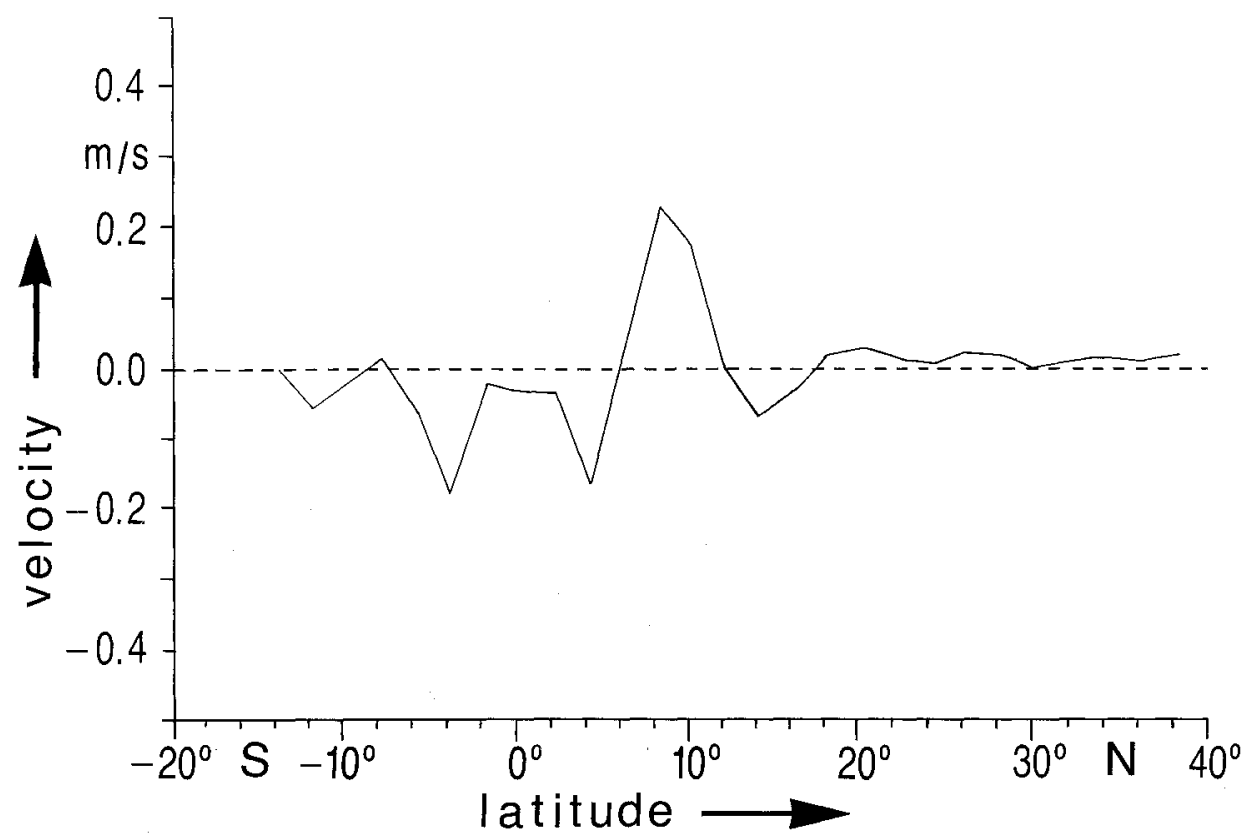

Fig. 4. An example of meridional zonal velocity (positive towards East) profiles showing the match between the first and second derivative velocity valculation procedures. 
While it is clear that the XBT spacing was not ideal for calculating the second derivative this was the only method available to compute velocities at the equator from the XBT data. The second derivative method was used within \pm 3 degrees of the equator, and the standard method of computing the geostophic velocity which was applied to XBT positions more than 2 degrees away from the equator. No really sharp discontinuities in the velocity sections became apparent. An example is shown in Fig. 4. We felt that our methods generally matched smoothly and that the inferred geostrophic velocities at the equator are not unreasonable.

\section{Time series}

An interesting presentation of the sea surface topography, and its gradient, is found in Fig. 5 where the dynamic height profiles are used to make a three-dimensional $(3 \mathrm{D})$ time series presentation. Here negative latitudes are south and the meridional profiles extend from $40^{\circ} \mathrm{N}$ to $20^{\circ} \mathrm{S}$. Beginning in 1980 these three $3 \mathrm{D}$ plots display the variations of the dynamic sea surface topography associated with the equatorial currents.

The general character of the XBT data is apparent in these $3 \mathrm{D}$ plots. Along with the mean meridional dynamic height decrease towards the north, from a peak at about $14^{\circ} \mathrm{S}$, the $3 \mathrm{D}$ plots exhibit a lot of smaller scale variability. Somes of these are likely due to undetected errors in single XBT casts. Such erroneous features are particularly obvious as small peaks in the latter halves of 1981 and 1982 north of the equatorial trough (about $10^{\circ} \mathrm{N}$ ). Combined with complete gaps in the data these smaller errors tend to make the time series quite noisy which suggests that care be taken in their interpretation.

There are, however, marked variations in the strong meridional gradients, associated with the Atlantic equatorial currents. These features are represented by more than a single XBT cast and appear sufficiently smooth to suggest their reality as an expression of true dynamic height variability. Thus the focus of this analysis will be on identifying and discussing these changes in meridional dynamic topography gradients, and hence in zonal geostrophic currents. In order to better appreciate the meaning of the quasi-meridional dynamic topography gradients in Fig. 5, these gradients were converted to zonal geostrophic currents using the method mentioned in the data section. These zonally directed currents are also shown in the $3 \mathrm{D}$ plot format as time seriess in Fig. 6 . Here positive velocities are directed eastwards while the negative valued troughs represent westward currents.

Again in this presentation the noisy character of the XBT data is obvious in even these spline interpolated averages. Small isolated peaks and valleys are found both north and south of the equator in all of the equatorial current systems. Most outstanding of these are the narrow peaks in the maximum of the North Equatorial Countercurrent (NECC) at about $4^{\circ} \mathrm{N}$ to $10^{\circ} \mathrm{N}$ which protrude up beyond all other velocity maxima. These sporadic extremes detract from the overall annual variability of the NECC apparent in the $3 \mathrm{D}$ plots (Fig. 6) as a consistent ridge, which emerges at about $9^{\circ} \mathrm{N}$ in Juni, following a much flatter expression of the eastward NECC between January and June. This pattern is consistent with earlier studies of the NECC annual cycle by Katz [1981] and Merle and Arna ult [1985].

Not all of the isolated sharp peaks in the NECC (Fig. 6) are necessarily due to XBT errors. The smaller features, in time and space, might be attributable to these errors but peaks, such as that found in March 1981 or those in the latter half (after June) of 1982, contain more than a single XBT value and most likely reflect shorter-scale variability of the NECC. Since most of these features last no more than a few weeks they may be expressions of mesoscale circulation phenomena embedded in the NECC and crossed by the XBT sections. Similar short-term, small-scale velocity features can also be found in the westward directed South Equatorial Current (SEC) located between the equator and $10^{\circ} \mathrm{S}$. Since these are hidden behind the ridge of the NECC, in Fig. 6, they are easiest to see in the dynamic topography (Fig. 5) where they appear as sharp increases in the southward upslope 
Fig. 5. Three-dimensional time series $(1980,1981,1982,1983,1984)$ of the $0 / 300$ dbar meridional dynamic height profiles. Heavy lines connect the dynamic height values along the latitude $6^{\circ} \mathrm{N}$ and $6^{\circ} \mathrm{S}$.
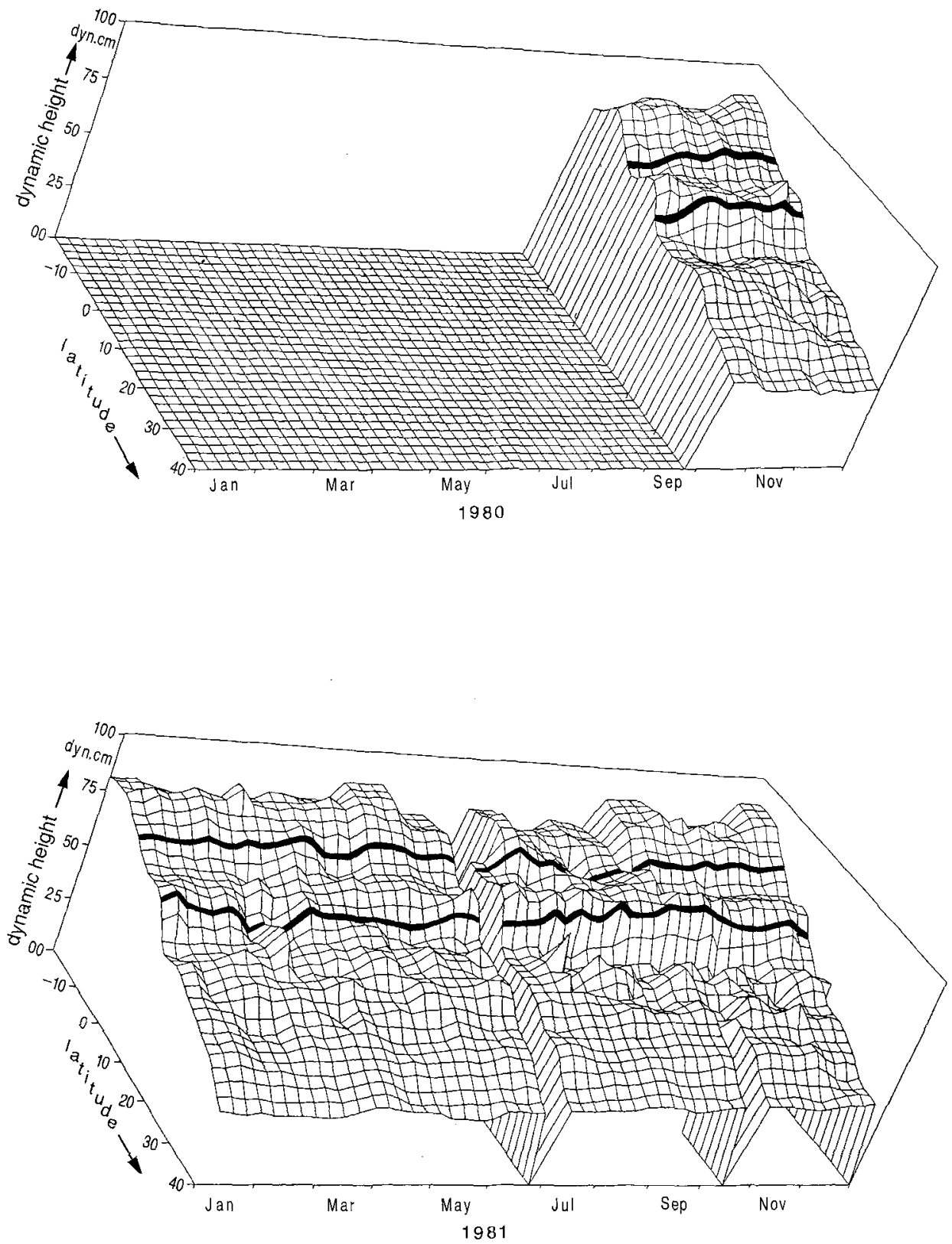

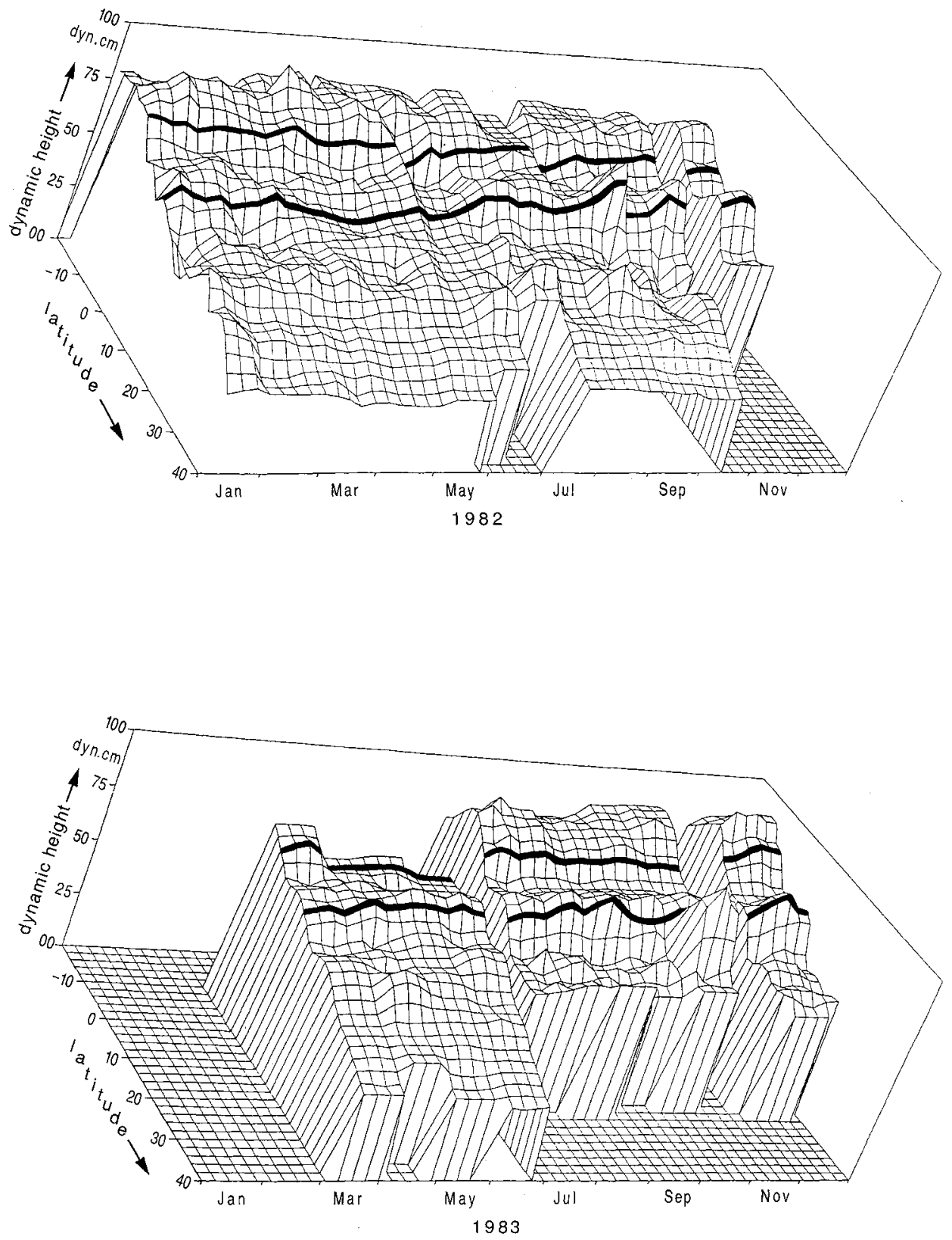


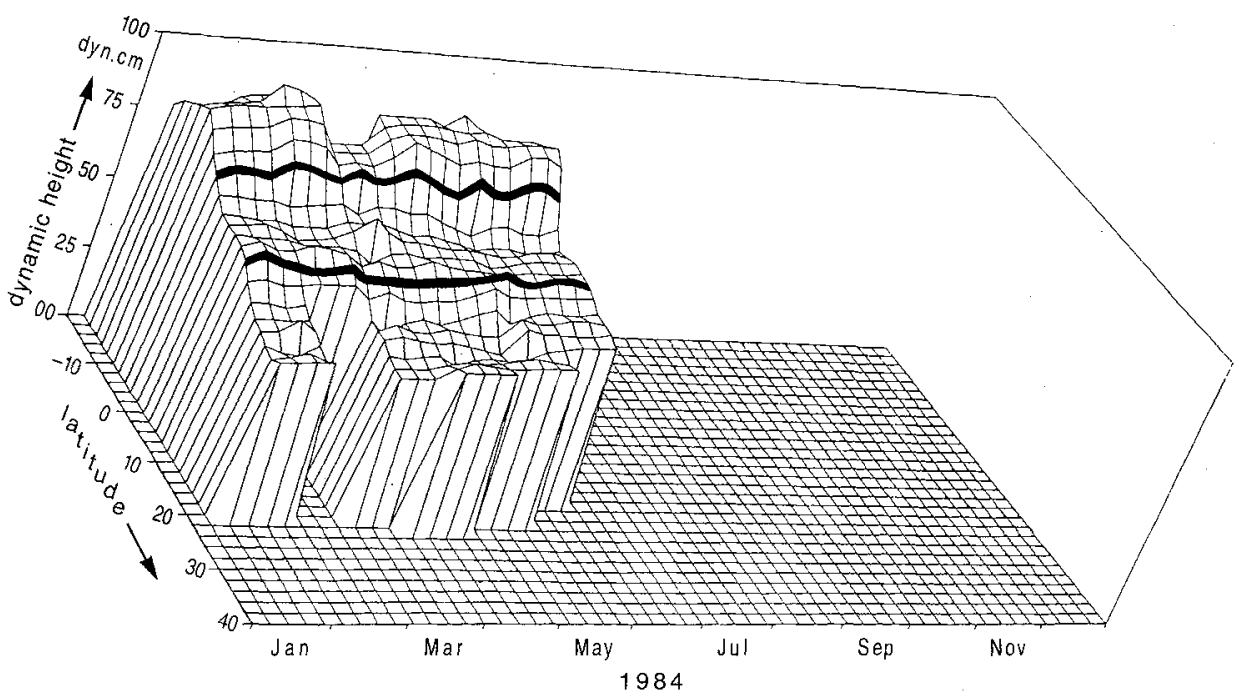

over this same latitude range. Examples of this interannual variability can be seen in July 1981 (stronger SEC) and early October 1981 (weak and eastward directed SEC). The latter of these two features stands out as a distinct positive peak in the display for 1981 in Fig. 6.

As with the NECC some of the larger variations in the strength of the SEC, shown in Fig. 6, are expressions of long-term trends. A dramatic example can be seen by comparing the starting January values for the SEC in Fig. 6 for 1981 and 1982. The westward flowing trough (negative velocities), at the start of 1981, is relatively shallow $(0.1 \mathrm{~m} / \mathrm{s})$ suggesting a weak SEC which appears to continue weak at least through the first half of 1981. In strong contrast 1982 begins with a deep trough $(0.25 \mathrm{~m} / \mathrm{s})$ indicating a strong SEC which continues strong until about May. This pattern for 1982 not only contrasts sharply with that in 1981 (where the SEC trough gradually deepens as the year progresses except for deviations in the fall of 1981) but also contrasts with the observations by Richardson and McKee [1984] and Richardson and Walsh [1986], that the SEC (at least its northern arm) oscillates in phase with the NECC strengthening after June to its peak in the fall. In spite of this apparent contradiction the sharp trough (and the corresponding westward SEC) are well developed and smooth at the beginning of 1982 (Fig. 6). Thus, significant interannual changes do occur in this part of the SEC. To continue this example the short series at the start of 1984 (Fig. 6) begins with a weak and shallow SEC which then rapidly deepens (westward directed SEC) until about April 1984. Unfortunately there is a large gap between November 1982 and March 1983 which makes it impossible to follow this same development at the beginning of 1983 .

The absence of a well developed and continuous trough, north of $6^{\circ} \mathrm{N}$ in the geostrophic velocities of Fig. 6, demonstrates how poorly these XBT sections resolve the North Equatorial Current (NEC). As can be seen from the sampling pattern in Fig. 1 the sections run almost paraallel to the NEC between $10^{\circ} \mathrm{N}$ and $20^{\circ} \mathrm{N}$ ( $\mathrm{R} \mathrm{i} \mathrm{ch} \mathrm{ardson} \mathrm{and} \mathrm{Walsh} \mathrm{[1986],}$ $\mathrm{Käse}$ et al. [1986]) and thus cannot resolve the corresponding cross-flow dynamic height gradient. In addition the NEC is weak in this region of the North Atlantic. Thus, it is difficult to decide whether the small negative (westward) velocity features, which appear in Fig. 6 at these latitudes, are expressions of variations in the strength the NEC or merely reflect noise in the XBT sampling. 
Fig. 6. Three-dimensional time series $(1980,1981,1982,1983,1984)$ of zonal geostrophic surface velocity relative to $300 \mathrm{dbar}$ meridional profiles (cf. Fig. 5). Currents towards the East are positive. Heavy lines connect the velocity values along the latitude $6^{\circ} \mathrm{N}$ and $6^{\circ} \mathrm{S}$.
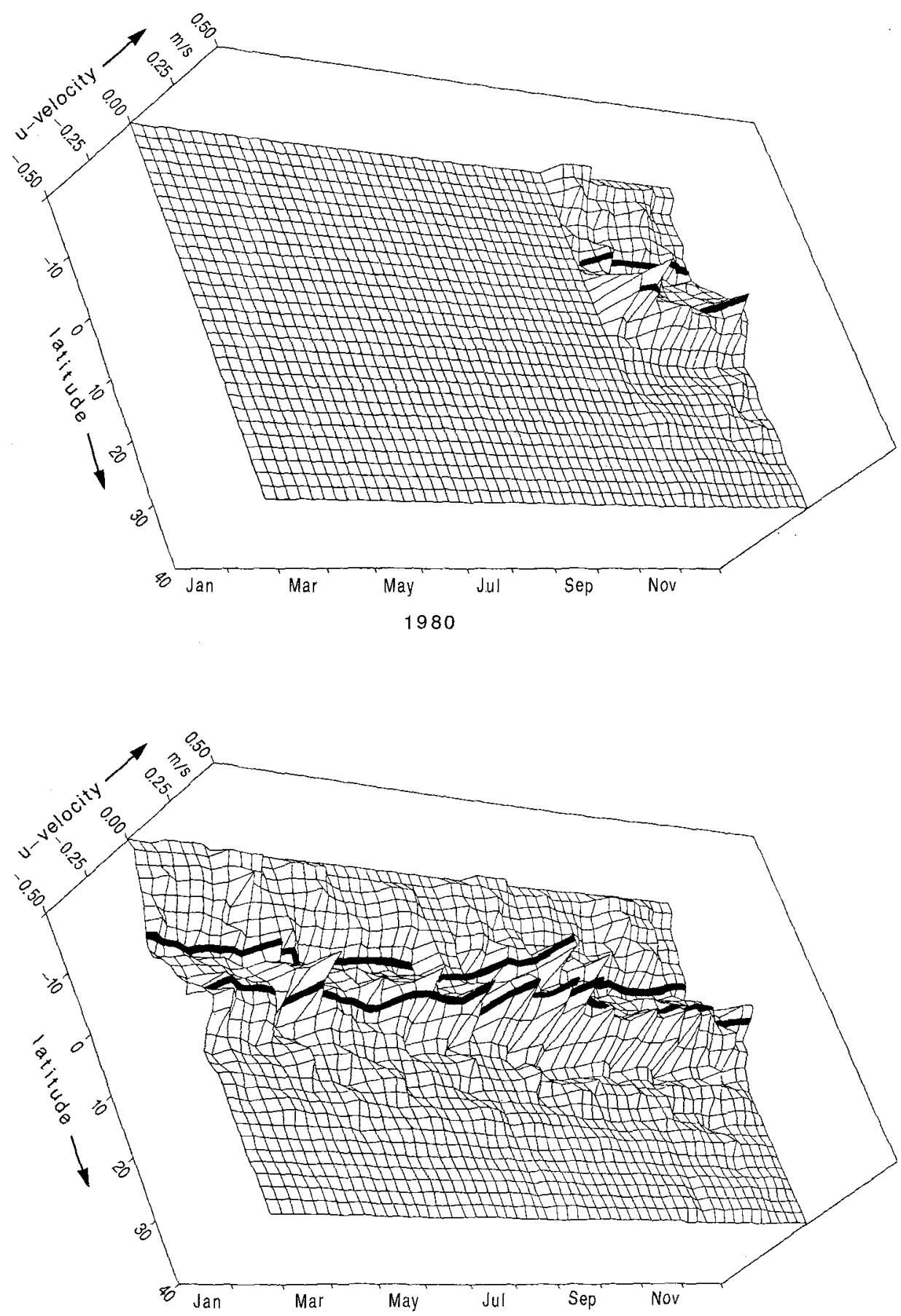

1981 

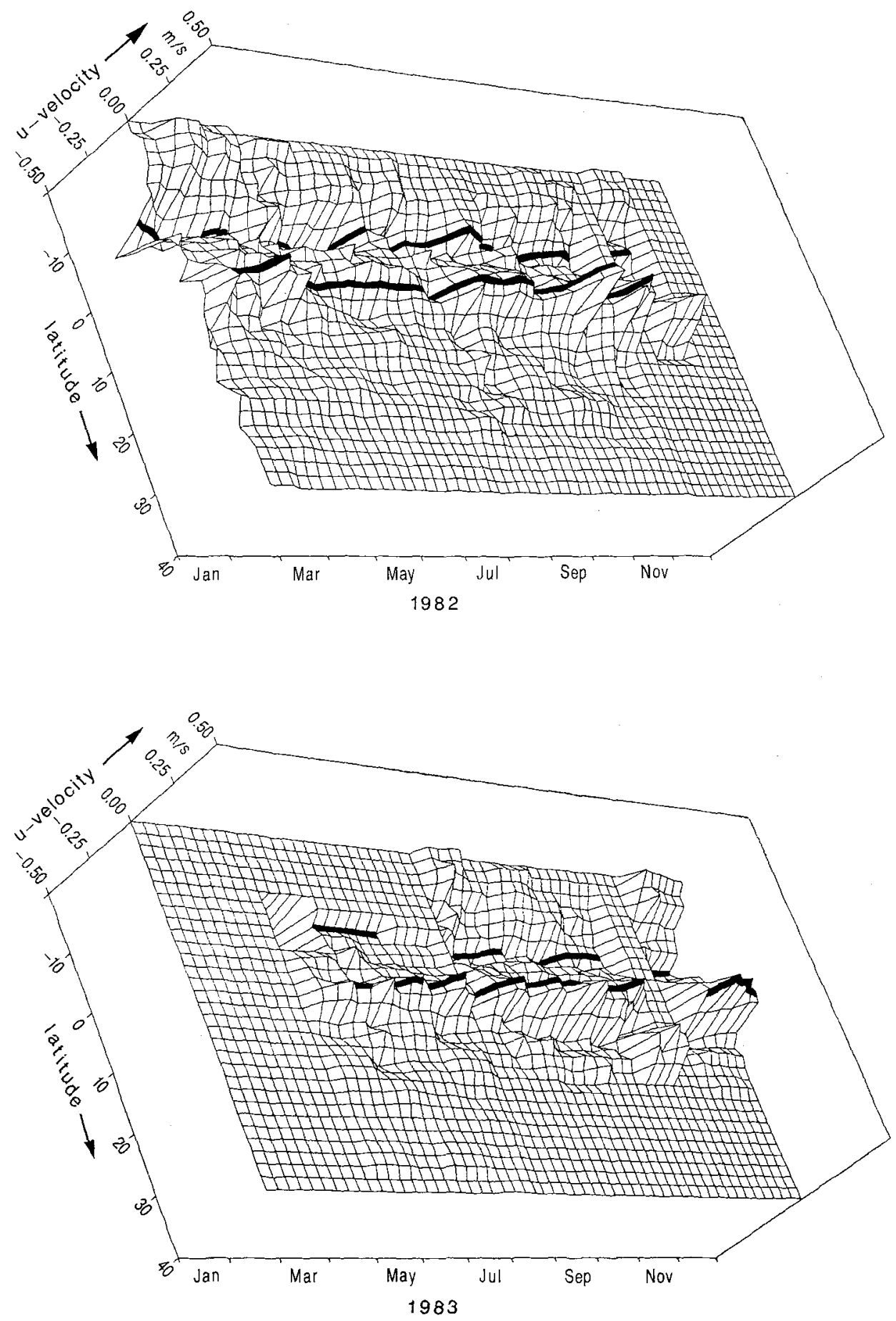


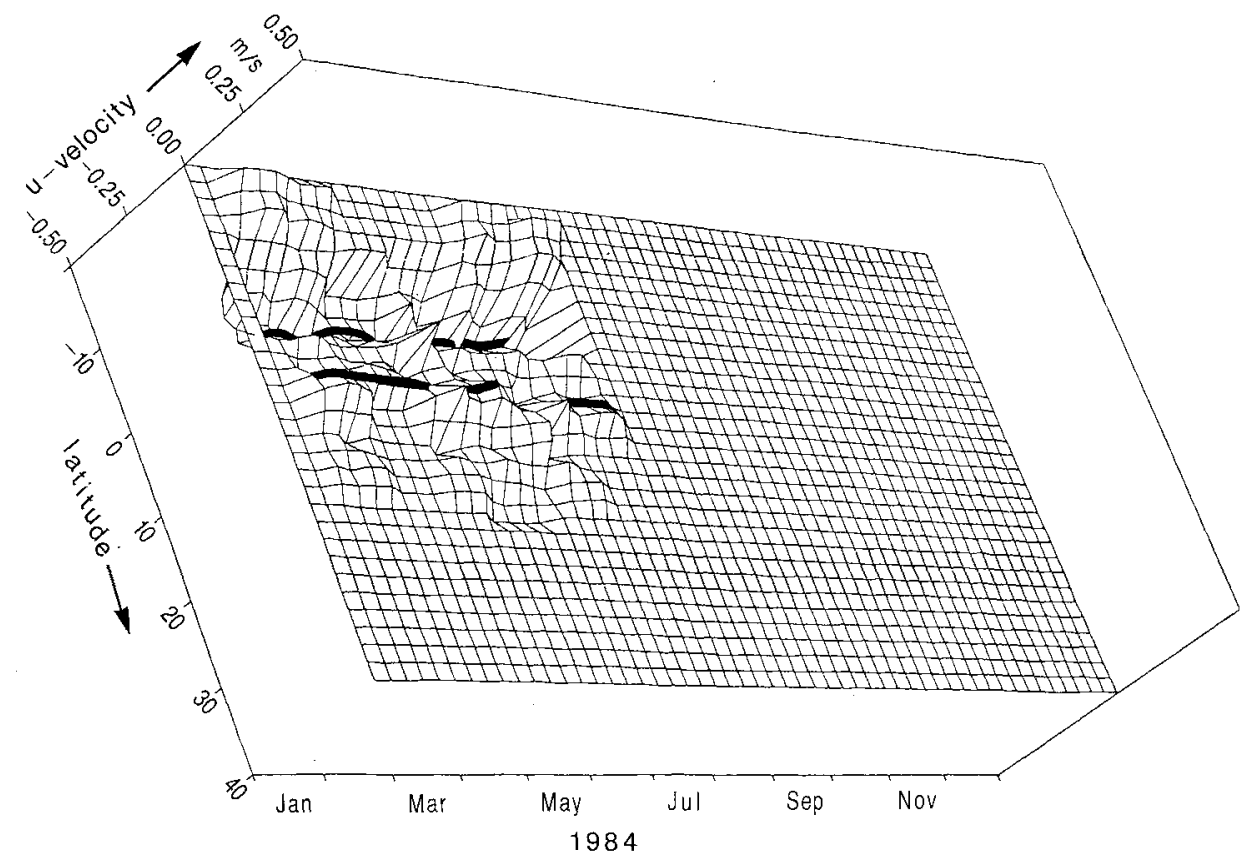

\section{Seasonal variations}

Summaries of seasonal patterns in the $0 / 300 \mathrm{db}$ dynamic topography are presented in Fig. 7. Points for each 2 degrees of latitude, are plotted as meridional profiles to represent the four seasonal and one annual mean profiles along with the standard deviations for each value. The seasons were defined with winter being December, January and February. These summary plots are the most statistically meaningful results of this study since repeated averaging reduces the influence of XBT data noise apparent in the $3 \mathrm{D}$ plots.

There are some interesting changes in this relatively smooth set of quasimeridional profiles. From the profiles in Fig. 7 we can see the positions of the important dynamic topography peaks and troughs as they shift both north and south with season and fluctate in magnitude. The annual mean profile exhibits peaks at $13^{\circ} \mathrm{S}$ and $4^{\circ} \mathrm{N}$ associated with the SEC and the NECC. The equatorial trough is found just south of the equator at about $2^{\circ} \mathrm{S}$. In winter the southern peak shifts slightly from $13^{\circ}$ to $14^{\circ} \mathrm{S}$ to $12^{\circ} \mathrm{S}$ with a further shift in the spring to $11^{\circ} \mathrm{S}$. In spring the northern peak (which was at $4^{\circ} \mathrm{N}$ in winter) weakens and almost competely disappears. In summer the norhtern peak returns rapidly to about $4^{\circ} \mathrm{N}$ where it remains through the fall. Meanwhile in summer the southern peak weakens and while there is still a maximum in dynamic height at about $4^{\circ} \mathrm{N}$, it is relatively smooth. The emergence of a fall southern peak, between $12^{\circ} \mathrm{S}$ and $14^{\circ} \mathrm{S}$, signals the return of the SEC. Of these peaks the maximum dynamic height value is found in the southern winter peak. The equatorial trough remains fairly constant in both magnitude $(0.7$ dyn $\mathrm{m})$ and location $\left(2^{\circ} \mathrm{S}\right)$. 

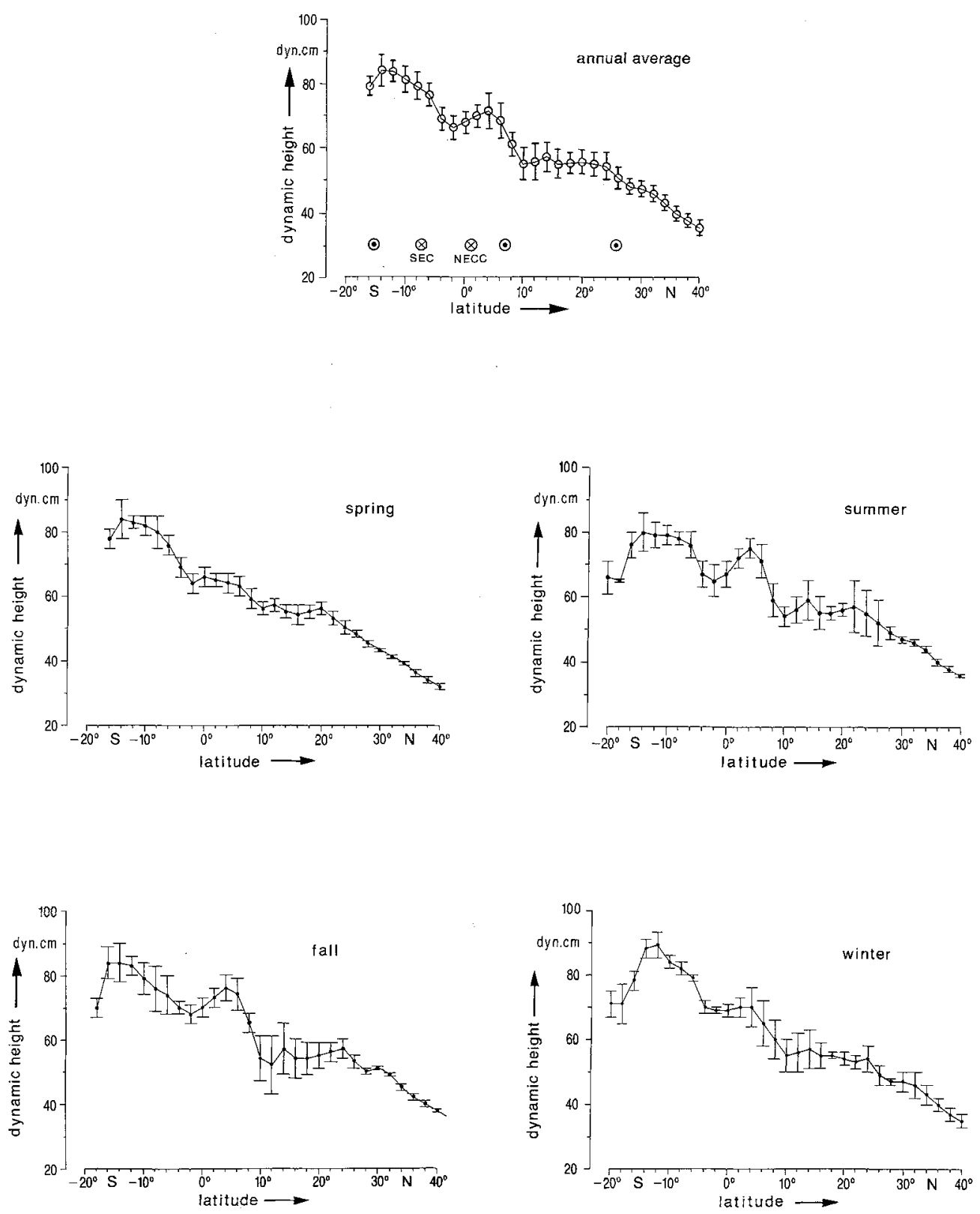

Fig. 7. Annual mean (top) and seasonal mean 0/300 dbar meridional dynamic height profiles in 2 degree averages. The standard deviation within each averaging interval is indicated. Circles with dots and crosses indicate zonal flow directions towards the east and west. 
The dynamic height variability, expressed by the standard deviations surrounding the mean values, is greatest in the fall and weakest in the spring. In spring both the mean dynamic height structure and the standard deviation are at a minimum. The annual mean meridional profile has its greatest variability in the NECC slope north of $4^{\circ} \mathrm{N}$ and in the peak of the SEC around $10^{\circ}$ to $14^{\circ} \mathrm{S}$. This overal is somewhat similar to that shown for winter. Summer and fall have sharper mean slopes between $6^{\circ}$ and $10^{\circ}$ to $12^{\circ} \mathrm{N}$ associated with the NECC. Interestingly the largest standard deviations are found to the north of the NECC trough $\left(10^{\circ} \mathrm{N}\right)$ in fall.

\section{Discussion}

Converted to $0 / 300 \mathrm{db}$ dynamic topography the four-year time series of XBT sections provides a useful summary of the variations in the surface topography across the central equatorial Atlantic. Unfortunately the spatial resolution and absolute temperature accuracy are not sufficient to produce precise geostrophic current estimates. In addition the $300 \mathrm{db}$ reference level dictated by the XBT temperature profiles is not correct for many of the equatorial currents and a certain amount of important current variability is ignored. Still within these limitations the time series of XBT profiles provides a unique depiction of changes in the quasi-meridional surface topography slopes associated with the equatorial currents.

Most of the results from the statistically meaningful annual mean description could have been anticipated from earlier studies. For example, the weakening to almost non-existence of the NECC in spring with its rapid return in summer (June) has been clearly documented by Richardson and McKee [1984] and Richardson and Walsh [1986]. Still the annual cycle from the XBT data in Fig. 7 adds the clear realization that the primary variability of this current is located on its southern border four degrees north of the equator.

Garzoli and Katz [1983], Delcroix [1986] and Busalachi and Picaut [1983] report that the thermal structure, associated with the NECC west of $25^{\circ} \mathrm{W}$, oscillates 180 degrees out-of-phase between the northern $\left(7^{\circ}\right.$ to $\left.10^{\circ} \mathrm{N}\right)$ and southern $\left(4^{\circ}\right.$ to $\left.7^{\circ} \mathrm{N}\right)$ limits of the current. In agreement the mean meridional dynamic topography profiles (Fig. 7) display a decrease in the dynamic height values around $7^{\circ}$ to $10^{\circ} \mathrm{N}$ simultaneous with an increase in dynamic height over the $4^{\circ}$ to $7^{\circ} \mathrm{N}$ portion of the profiles. This out-of-phase relationship between the two ends of the NECC is even clearer in the $3 \mathrm{D}$ dynamic topography on Fig. 5. For example from 1981 to 1983 a deepening of the NECC trough, coincident with an increase in the NECC peak, marks the strengthening of the countercurrent. Near the end of 1981 the NECC peak drops as the trough shallows revealing an overall weakening of the current. In 1982 this out-of-phase relationship appears to hold not only in general but also for individual dynamic height anomalies.

The mean annual meridional dynamic height structure, displayed in the top panel of Fig. 7, is consistent with a study by Merle and Arna ult using a comprehensive set of historical temperature profiles and hydrographic data. Due to the location and orientation of the XBT sections the topographic high at $20^{\circ} \mathrm{N}$, reported by $\mathrm{Merle}$ and Arnault, is not well developed in Fig. 7 and instead appears only as a rather flat portion of the meridional profile. The low at $10^{\circ} \mathrm{N}$, the high between $2^{\circ} \mathrm{N}$ and $3^{\circ} \mathrm{N}$ and the high from $2^{\circ}$ to $3^{\circ} \mathrm{S}$, identified by $\mathrm{Merle}$ and A r n u lt [1985], are all faithfully represented by the mean annual $0 / 300 \mathrm{db}$ dynamic height profile. This excellent agreement provides added confidence that when noisy and error-prone XBT data are sufficiently averaged they can provide a useful and accurate description of the equatorial current systems. This further strongly suggests that the seasonal depictions of dynamic topography are representative and that the seasonal variability is well resolved. This is a unique depiction of the seasonal signal in the strength and position of the zonal Atlantic equatorial currents between 1980 and 1984 made possible by the repeated XBT sections. 
As a result of the many smaller scale errors seen in the detailed dynamic height and geostrophic current plots, for the present study, a recommendation is made that the frequency of XBT sampling along the SOOP sections be increased to provide more data for averaging and smoothing. In addition an effort should be made to arrange the XBT casts positions such that they are fairly uniformly distributed over the sample space and time, allowing averaging to produce unbiased results. Only by continuing and improving these SOOP XBT programs can we gain insight into the variability of the baroclinic structure associated with the zonal equatorial currents.

\section{Acknowledgements}

This study began while W. J. Emery was a sabbatical visitor at Kiel University. This visit was supported by the Deutsche Forschungsgemeinschaft (SFB 133). Data processing and calculations partly were carried out by P. Gallis, M. Kleinicke, M. Prive and N. Zangenberg. The collection of the XBT sections originally was carried out by both German and French merchant ships and the participation of these ships and their crews is gratefully acknowledged. The financial support of PNECD and O.R.S.T.O.M. made data collection possible. Much of the final analysis was performed at the University of British Columbia (NSERC). Comments on earlier versions of the manuscript from T. Delcroix, C. Henin, J. Picaut, E. Fahrbach and R. Hought were most helpful.

\section{References}

Arnault, S., 1984: Variation saisonniere de la topographis dynamique et de la circulation superficielle de l'Ocean Atlantique Tropical. Thesis 3ieme Cycle, Univ. of Paris IV.

Busalachi, A. J. and J. Picaut, 1983: Seasonal variability from a model of the Tropical Atlantic Ocean. J. Phys. Oceanogr. 13, 1564-1588.

Delcroix, Th., 1986: The North Equatorial Countercurrent inferred from dynamic height and thermocline depth. Tropical Ocean-Atmosphere News. 34, 5-6.

Emery, W. J. and J. S. Dewar, 1982: Mean temperature-salinity, salinity-depth and temperature-depth curves in the North Atlantic and North Pacific. Prof. Oceanogr. 11, 219-305.

Garzoli, S. L. and E. J. Katz, 1983: The forced annual reversal of the Atlantic North Equatorial Countercurrent. J. Phys. Oceanogr. 3, 2082-2090.

Käse, R. H., J. F. Price, P. L. Richardson and W. Zenk, 1986: A quasisynoptic survey of the thermocline circulation and water mass distribution within the Canary Basin. J. Geophys. Res. 91, 9739-9748.

Katz, E. J., 1981: Dynamic topography of the sea surface in the equatorial Atlantic. $\mathbf{J}$. Mar. Res. 39, 53-63.
Lukas, R. and E. Firing, 1984: The geostrophic balance in the Pacific Equatorial Undercurrent. Deep-Sea Res. 31, 61-66.

Merle, J. and S. Arnault, 1985: Seasonal variability of the surface dynamic topography in the tropical Atlantic Ocean. J. Mar. Res. 43, 267-288.

Richardson, P. L. and R. G. McKee, 1984: Average seasonal variation of the Atlantic equatorial currents from historical ship drift. J. Phys. Oceanogr. 14, 1226-1238.

Richardson, P. L. and D. Walsh, 1986: Mapping climatological seasonal variations of surface currents in the tropical Atlantic using ship drift. J. Geophys. Res. 91, 10537-10550.

Rual, P. and R. Jarrige, 1984: Tropical Atlantic thermal structure along the EuropeBrazil ship line. Geophys. Res. Let. 11, $775-778$.

Tsuchiya, M., 1955a: On a simple method of estimating the current velocity at the equator. J. Oceanogr. Soc. Japan. 11, 1-4.

Tsuch iy a, M., 1955 b: On a simple method for estimating the current velocity at the equator. Res. Oceanogr. Works Japan. 2, $347-42$. 
Eingegangen am 10. März 1988

Angenommen am 8. Juli 1988

Anschrift der Verfasser:

Dr. William J. Emery

CCAR Box 431, University of Colorado, Boulder, CO 80309, USA

Dr. Walter Zenk

Institut für Meereskunde der Universität Kiel, Düsternbrooker Weg 20, 2300 Kiel 1

Dr. Klaus Huber

Deutsches Hydrographisches Institut, Bernhard-Nocht-Straße 78, 2000 Hamburg 4

Dr. Pierre Rual

Centre O.R.S.T.O.M., BPA5 Noumea, New Caledonia, France

Dr. Paul Nowlan

Department of Oceanography, University of British Columbia, Vancouver, B.C. V6T 1W5, Canada 